\title{
ASPECTOS DA REGULAMENTAÇÃO DO USO MILITAR DAS NANOTECNOLOGIAS
}

\author{
Cristian Ricardo Wittmann ${ }^{1}$ \\ Wilson Engelmann²
}

\begin{abstract}
Resumo
O presente ensaio objetiva identificar desafios da regulação das nanotecnologias por meio da metodologia construtivista apoiada na matriz epistemológica pragmático-sistêmica. Comenta acerca das nanotecnologias enquanto inovação científica que proporciona, consequentemente, o seu uso militar. Aborda as dificuldades da inserção de tais preocupações por meio da regulamentação pública estatal e aborda novas perspectivas regulatórias por meio de instrumentos jurídicos pulverizados na sociedade global. Aborda-se dessa forma os programas de integridade como forma de regulação coordenada com os esforços públicos neste cenário organizacional transnacional.
\end{abstract}

Palavras-chave: nanotecnologias; regulação; compliance programs; programas de integridade; programas de compliance; armas;

\section{LEGAL ASPECTS ON THE REGULATION OF THE MILITARY USES OF NANOTECNOLOGY}

\begin{abstract}
The present essay aims to identify challenges of the regulation of nanotechnologies through constructive methodology, with sinergy with the pragmatic-systemic epistemological matrix. It comments on nanotechnology as a scientific innovation that, consequently, provides its military use. It addresses as difficulties of insertion of concerns through state public regulation and approaches new regulatory perspectives through legal instruments pulverized in the global society. Compliance programs are thus approached as a form of coordinated regulation with the public public systems in the transnational organizational scenario.
\end{abstract}

Keywords: Nanotechnologies; regulation; Compliance programs; Compliance; Military uses; Weapons;

\footnotetext{
${ }^{1}$ Doutor em Direito (UNISINOS). Professor Adjunto e Diretor de Assuntos Estratégicos, Relações Institucionais e Internacionais da Universidade Federal do Pampa (UNIPAMPA). Advogado.

${ }^{2}$ Doutor em Direito. Professor da Universidade do Vale do Rio dos Sinos (UNISINOS). Coordenador Adjunto do Programa de Pós-Graduação em Direito - Mestrado em Doutorado - da UNISINOS. Coordenador do Mestrado Profissional em Direito da UNISINOS. Bolsista Produtividade em Pesquisa CNPq.
} 


\section{INTRODUÇÃO}

O presente ensaio científico, fruto de tese doutoral em Direito, busca ao mesmo tempo identificar aspectos jurídicos atinentes ao uso militar das nanotecnologias mesmo em um cenário de regulação mínima quanto elencar o cenário jurídico global contemporâneo propício ao endereçamento de seus desafios. Inicialmente se propõe a identificar aspectos relevantes das nanotecnologias, passando por seus potenciais usos militares e por fim aspectos de sua regulação.

Inevitavelmente a inovação tecnológica não possui grandes restrições de aplicação - seja ela qual for. A falta de marcos jurídicos restritivos geralmente coloca-se como liberdade para a conveniência e oportunidade do agente. Em tratando-se de nanotecnologias existe, além do risco associado a um novo paradigma tecnológico aplicável a todos os ramos, também a dificuldade da estabilização das expectativas jurídicas envolvendo o cenário global e, em especial, o campo de aplicação bélica.

A partir do ponto de vista clássico tem-se que observar o papel protagonista do Estado na regulamentação dos interesses. E no cenário bélico isso normalmente envolve uma perspectiva entre Estados, não por menos do termo inter"nacional" - cenário de exclusividade esse classificado como insuficiente. O marco jurídico aplicável é analisado e, ampliando-se o escopo de análise da produção e decisão jurídica no marco global, aponta-se a necessidade de uma atualização da regulamentação à regulação.

Entre a complexidade social e a função dos sistemas sociais optou-se pela matriz epistemológica pragmático-sistêmica (ROCHA, 2003) e a metodologia construtivista (LUHMANN, 2007) pelo aporte qualificado para observar a ciência jurídica na contemporaneidade. Considerando o exposto, por problemática a ser compreendida optou-se pelo seguinte questionamento: dentre as possibilidades de regulação das nanotecnologias em usos militares, a exclusividade da regulamentação estatal pública ainda se mostra eficiente?

Este ensaio está estruturado na forma de três capítulos de forma a contemplar análise sobre os três pilares anunciados. A nanotecnologia, o uso militar e os aspectos jurídicos são percebidos sem a dissociação da perspectiva metodológica construtivista proposta. Ressalta-se que o aprofundamento do neste ensaio apresentado pode ser 
buscado na tese doutoral apresentada e depositada no banco de dados digital do Programa de Pós-Graduação cursado pelo autor.

\section{NANOTECNOLOGIA E DIREITO}

A nanociência trabalha com tecnologias em que seus produtos se apresentam em uma dimensão nunca antes pensada, ou seja, um bilionésimo de metro: "[...] nanotecnologia é a compreensão e o controle da matéria em dimensões aproximadamente entre 1 e 100 nanômetros" (BORGES, et all, 2014, p. 6). Neste aspecto tais tecnologias “[...] prospectam a produção de objetos, equipamentos e produtos que estão aproximadamente em torno da escala de 1 a 100 nanômetros $(\mathrm{nm})$, ou seja, $10^{-9}$ de ordem de grandeza" (ENGELMANN, 2010, p. 299).

De forma a ilustrar melhor a ordem de grandeza, exemplifica-se que um fio de cabelo humano possui em torno de 50 mil nanômetros. Já a célula bacteriana possui algumas centenas de nanômetros. Os chips comercializados ainda em 2004 possuíam padrões menores de 100 nanômetros. Ao olho nu somente são perceptíveis objetos que têm cerca de 10 mil nanômetros. Claramente trata-se de uma escala de grandeza que hoje supera, e muito, a imaginação sobre o próprio átomo.

É clara a relação entre nanociência e nanotecnologia. Essa representa o resultado daquela. Nanotecnologia seria um termo abrangente que, como um guarda-chuva, abrange uma grande diversidade de tecnologias a partir da nanociência. Enquanto a nanociência possui como cerne a compreensão das ditas novas propriedades dos materiais quando em nanoescala, a nanotecnologia trata de explorar aplicações como a criação de estruturas, dispositivos e sistemas a partir dessas novas propriedades, assim como argumenta Flávio Peixoto:

Espera-se que a nanotecnologia surja das descobertas da nanociência. Ela
representa a convergência da física quântica, biologia molecular, ciência da
computação, química e engenharia. As inovações advindas da nanociência
costumam ser comercializadas à medida que o controle sobre a construção de
átomos e das moléculas melhoram. Da mesma forma que os compuadores
analisam e distribuem dados num formato binário $(0,1)$, a nanotecnologia trata
da construção de novos materiais (orgânicos e inorgânicos) ao tratar átomos e
moléculas como blocos de construção. (PEIXOTO, 2013, p. 67)

Devido a característica de que os resultados das tecnologias em nanoescala serem normalmente utilizados como insumos nas manutafutras tradicionais ou em seus processos de produção, seu impacto deve ser analisado em conjunto com aqueles componentes tradicionais, ou seja, sem o uso das nanotecnologias. Da mesma forma 
identifica-se que o impacto será limitado ao escopo dos componentes que não possuem nanotecnologia. Por esse motivo as nanotecnologias podem ser consideradas como um incremento nas diversas tecnologias industriais existentes. (PHOENIX, et all, 2008)

Todavia têm-se observado que a mesma substância no nível molecular se comporta de modo distinto. Existem alterações significativas também quando do comportamento dos átomos e elétrons na matéria. A partir da teoria quântica existe o comportamento deles como ondas, claramente perceptíveis nas dimensões nanométricas. Quando de amostras com um número reduzido de átomos esse comportamento se assemelha às vibrações de uma corda de violão. Isso vai ter uma consequência direta sobre as distintas características físicas daquela amostra nanoscópica, como sua cor e a condutividade elétrica. Ainda como exemplo das alterações das características da matéria usualmente conhecida em dimensões ordinárias, chama-se a atenção para os denominados efeitos de superfície que implicam efeitos aceleradores ou retardadores, ou seja, na eficiência dos processos de catálise.

Os riscos associados às nanotecnologias se dividem em duas grandes esferas que, em certa medida, se aproximam dos atuais riscos industriais. A primeira categoria estaria associada a disponibilidade e uso de produtos. A segunda, por sua vez, diz respeito aos danos não esperados. Quando da disponibilidade e uso de produtos há a possibilidade indireta de, a partir da nanotecnologia, tornar tais prejuízos maiores e perigosos conforme a vontade do fabricante - especialmente em se tratando de usos militares. Já os riscos de danos inesperados trazem o caráter da imprevisibilidade, desafiando a compreensão de risco e responsabilidade normalmente fundados na previsibilidade entre o Direito e a Política.

The risks of nanoscale technologies appear in two broad classes, which are analogous to existing industrial risks. The first class is risks resulting from the availability and use of the eventual products. In this way, the nanoscale technology contributes only indirectly, by making products more powerful, more dangerous, more widely used, and so on. The second class is risks resulting from new materials that may cause inadvertent harm. (PHOENIX, et all, 2008, p. 483)

Neste debate entre nanotecnologias, inovação tecnológica, sociedade de risco e equidade intergeracional reside a grande celeuma da modernidade. Uma complexidade sistêmica inédita que, todavia, ingressa no ambiente jurídico por meio da compreensão dos riscos que envolvem e ameaçam o direito à sustentabilidade. Não resta dúvida que o risco está associado às possibilidades de decidir, fazendo então a 
diferenciação entre risco e perigo quando de decisões contingentes - na sociedade complexa o risco torna-se um elemento decisivo:

O risco é um evento generalizado da comunicação, sendo uma reflexão sobre as possibilidades de decisão. Na literatura tradicional, o risco vem acompanhado da reflexão sobre segurança. Nesta ótica, Luhmann prefere colocar o risco em oposição com o perigo, por entender que os acontecimentos sociais são provocados por decisões contingentes (poderiam ser de outra forma), que não permitem mais se falar de decisão segura. (grifo do autor) (ROCHA, et all, 2005, p. 36)

Risco está associado à perda potencial como consequência de uma decisão, ao ponto que perigo se atrela às perdas potenciais causadas externamente. Tendo em vista os conceitos de racionalidade na identificação dos riscos, sugere-se logicamente que a sociedade moderna pode ser considerada uma sociedade de risco, ao ponto em que as sociedades antigas são abordadas como sociedades de perigo, tendo em vista a não existência de percepção na identificação das possibilidades de perda frente às decisões tomadas.

Esses conceitos se tornam pertinentes no momento em que se encontra uma sociedade de risco em contrapartida do fato da sociedade industrial ter se tornado obsoleta, ou seja, vive-se "[...] uma fase no desenvolvimento da sociedade moderna, em que os riscos sociais, políticos, econômicos e individuais tendem cada vez mais a escapar das instituições para o controle e a proteção da sociedade industrial"(BECK, 1997, p. 15).

A diferença de uma sociedade moderna, diferenciada em classes, da sociedade de risco é que ao contrário da riqueza a racionalidade passa a estar associada à exposição ao risco. Não guarda grande diferença o cenário de incerteza das alterações do ambiente que ampliam as possibilidades catastróficas do contexto duvidoso trazido pelas nanotecnologias:

[...] o risco é um conceito que tem sua origem na modernidade, dissociando-se de uma dimensão de justificação mítica e tradicional da realidade, relacionada com a verificação de contingências, eventos naturais e catástrofes, atribuídos a causas naturais e à intervenção divina, para se aproximar de uma dimensão que seleciona como objetos as consequências e os resultados de decisões humanas [...] e que se encontram associadas ao processo civilizacional, à inovação tecnológica e ao desenvolvimento econômico gerados pela industrialização. (LEITE; AYALA, 2004, p. 12-13)

Mesmo sendo a nanotecnologia um elemento em largas estruturas manufaturadas, inclusive nas geralmente mais resistentes a impactos, pode haver um dano não intencional potencializado por nanopartícula quando por exemplo um impacto inesperado, explosão dentre outras possibilidades (Cf. NASU, 2016). 
Even if ENMs are firmly embedded in larger structures and are therefore difficult to separate from the structural components, strong physical impacts may well result in an accidental release of hazardous ENMs and ENPs when targeted by kinetic means or as a result of fire. Upon release, ENMs and ENPs may enter into human bodies through inhalation, and also into the environment with the real possibility that nanomaterials may move through food chains and culminate in human exposure.

Em não sendo possível iniciar o futuro, inserido nesta perspectiva luhmanniana, é preciso que os sistemas sejam capazes não somente de gerir a responsabilidade e risco, mas também a aprendizagem dinâmica. Por esse motivo é que se torna primordial na atualidade a adoção de uma perspectiva sociológica da decisão e da responsabilidade que leve em conta a contingência e aprendizagem. Uma alternativa para essa proposta é buscar outras formas funcionalmente equivalentes de responsabilidade que possam, frente a forma operacionalmente fechada de cada sistema/organização, irritar tais sistemas para que apreendam de forma mais rápida e qualificada. (Cf. BORA, 2012)

\section{USOS MILITARES E O CONTEXTO REGULAMENTATÓRIO INTER"NACIONAL"}

A relação entre o desenvolvimento tecnológico e as forças armadas mantêm-se como uma característica constante na história da guerra. O desenvolvimento tecnológico justamente pode ser estimulado na tentativa de suprir necessidades militares. De outro lado também existe o estímulo de condutas militares por meio de inovações externas ao ambiente militar tradicional, alterando as táticas de países desenvolvidos:

The interaction between technological development and armed forces is a constant feature of the history of warfare. Technological development can be stimulated by, and dedicated directly to addressing, military requirements. On other occasions, technological development outside the military sphere affects or informs the conduct of warfare and military expectations, as has been illustrated by the application of computing and software innovations that have led to major changes in the military tactics of developed nations. (NASU, 2012, p. 654)

Os usos militares das nanotecnologias são os mais variados. Embora o acesso a informações acerca destas aplicações seja raro, inclusive por interesses econômicos e de soberania política, é possível verificar a grande gama de produtos e a verdadeira revolução bélica-industrial (Cf. HENLEY, 2000). Um dos grandes teóricos, Eric Drexler, abordou já em 1986 em seu livro "Engines of Creation" as nanotecnologias como máquinas de destruição como um de seus capítulos, bem como estratégias $e$ sobrevivência em outro, nos quais analisou a possibilidade de poder militar a partir de 
replicadores e sistemas de inteligência artificial com o desenvolvimento de armas avançadas e eventual guerra bacteriológica e outros mecanismos de design, estratégia e guerra. (Cf. DREXLER, 1986)

Em sendo possível a manipulação molecular, ela será usada para a produção de armas. Certamente provocará uma corrida armamentista já que não é somente um dos lados politica e militarmente antagônicos estarão desenvolvendo aplicações que qualificam sua possibilidade de impacto:

If molecular manufacturing works at all, it surely will be used to build weapons. A single manufacturing system that combines rapid prototyping, mass manufacturing, and powerful products could provide a major advantage to any side that possessed it. If more than one side had access to the technology, a fast-moving arms race could ensue. (PHOENIX; et all, 2008, p. 489)

As preocupações são as mais diversas e em relação direta com a quantidade de aplicações possíveis. Altmann aponta que as verificações de aplicações nanotecnológicas serão difíceis, mas não impossíveis - similar ao que é necessário para armas biológicas mas em uma escala sem precedentes, impondo a necessidade, segundo o autor, de um profundo código de ética e a coragem para sua aplicação se necessário ${ }^{3}$.

A relevância para aplicações militares das nanotecnologias, assim como nas aplicações genéricas, está na qualificação das capacidades militares já existentes. Não é exclusivo da nanotecnologia, já que o desenvolvimento tecnológico para fins bélicos sempre vai buscar de alguma forma a maior sobrevivência e proteção do soldado e do maquinário como um todo, a mobilidade da força, bem como a capacidade de aplicação e a precisão do uso da força. A bsuca de armaduras ou roupas leves, resistentes e com capacidade de automedicação são exemplos de apoio da nanotecnologia, não exclusivamente. Explosivos que ultrapassem determinadas armaduras, armamento autoguiado são outros exemplos citados por Hitoshi Nasu:

The relevance of nanotechnology to the military resides particularly in its application to enhance military capabilities including:

- soldier survivability (for example, lighter, stronger, and heat-resistant armour and clothing);

- force protection (for example, enhanced camouflaging, undetectable coating of aircrafts, explosive detectors, bio/chemical sensors);

- force mobility (for example, miniaturization of communication devices, increased energy generation and storage capacity);

\footnotetext{
3 "Verification would be difficult, but not unsolvable - similar to that needed for biological weapons, but on an unprecedented scale, raising tensions with individual privacy and the desire for propri- etary information. Scientists and engineers would need to adopt a strong code of ethical conduct, and to have the courage to blow the whistle if necessary." (ALTMANN, 2006, p. 11)
} 
- $\quad$ penetration capability (for example, nano-energetic explosives, armourpiercing projectiles coated with a nano-material); and

- focused force application (for example, 'nano air vehicles', self-guiding bullets). (NASU, 2012, pp. 656-657)

Uma das questões centrais dos usos militares das nanotecnologias é o equilíbrio em defesa e ataque. Em geral a defesa se mostra muito mais acessível e fácil de ser realizada que um ataque. Entretanto a controvérsia se estabelece, pois, já que equipamentos militares para defesa exigem uma maior quantidade de recursos. Da mesma forma que em qualquer produto, o aumento da resistência de material irá aumentar a funcionalidade e eficiência dos mais distintos tipos de armas. Embora essas novas armas possam mudar o foco com o qual os campos de batalha são organizados, novos campos de batalha surgirão, e provavelmente irão sobrecarregar a população civil. Toma-se por exemplo a mudança que os atuais conflitos proporcionaram, onde não mais se visualizam campos de batalha, e sim batalhas em meio a grandes centros urbanos e densamente povoados. (ICRC, 2005)

Embora a potencial característica tóxica das nanotecnologias que podem ser implementadas, não existe muitos estudos acerca da plausibilidade de uma arma completa produzida em nanoescala e que poderia matar em grande escala. Justamente os nanobots como robôs minúsculos que poderiam se autoreplicar e funcionar como outras armas tradicionais como minas terrestres, bombas cluster ou até mesmo gás venenoso são uma das controvérsias das possibilidades de existência:

To date, there does not appear to have been a detailed study of molecular manufacturing-built weapons published, but it seems plausible that a single briefcase full of weaponry could kill a large percentage of a stadium full of unprotected people (to take one scenario among many that could be proposed). Small robots could implement some of the worst properties of land mines (delayed autonomous action), cluster bombs (dispersal into small lethal units), and poison gas (mobile and requiring inconvenient degrees of personal protection). A wide variety of other weapons may also be possible, but this will suffice to put a lower bound on the apparent potential destructive power of molecular manufacturing-built products. (PHOENIX, et all, 2008, p. 488)

Além desses dilemas, existe uma questão importante acerca da miniaturização, ou seja, a possibilidade de ter reduzido à escala nanométrica os mais diversos bens, robôs e produtos dos gêneros. Bill Joy comenta que é necessário chegar a um acordo sobre o fato que a maior parte das tecnologias do Século XXI implicam em diferentes ameaças que quaisquer outras tecnologias anteriores, em especial a robótica aliada aos nanobots que posem se autorreplicar. Essa característica permitiria uma ameaça maior que a de 
uma bomba, já que ao passo que essa explode os nanobots ao se replicarem ficam fora de controle rapidamente:

we have yet to come to terms with the fact that the most compelling 21 stcentury technologies - robotics, genetic engineering, and nanotechnology pose a different threat than the technologies that have come before. Specifically, robots, engineered organisms, and nanobots share a dangerous amplifying factor: They can self-replicate. A bomb is blown up only once - but one bot can become many, and quickly get out of control. (JOY, 2016)

A questão da minituarização alertada por Joy Bill foi posteriormente analisada por Drexler. A ideia central seria a possibilidade de pequenos, autônomos, móveis, autoreplicadores poderiam serem capazes de recriarem para além do controle humano. $\mathrm{O}$ perigo estaria na posibilidade teórica de uso intencional como arma ou por simples curiosidade. Dependendo das características destas miniaturas, ou nanobots, será difícil de serem destruídas, ou seja, eliminadas até mesmo porque podem ser não suscetíveis à digestão biológica e dessa forma perpetuar-se com sucesso:

An idea that has caused significant concern (Joy, 2000) since it was introduced
two decades ago (Drexler, 1986) is the possibility that small, self-contained,
mobile, self-copying manufacturing systems might be able to gain suf cient
resources from the ecosphere to replicate beyond human control. Drexler's
original concern of accidental release was based on a now-obsolete model of
manufacturing systems (Phoenix and Drexler, 2004). However, there is at least
the theoretical possibility that someone will design and release such a thing
deliberately, as a weapon (though for most purposes it would be more
cumbersome and less effective than non-replicating weapons) or simply as a
hobby. Depending on how small such a device could be made, it might be quite
dif cult to clean up completely; furthermore, if made of substances not
susceptible to biological digestion, it might not have to be very efficient in
order to perpetuate itself successfully. (PHOENIX, et all, 2008, p. 488) Uma preocupação crescente é a possibilidade de manipulação molecular para desencadear agentes biológicos e químicos. Tais propriedades são capazes de produzir consequências humanitárias, já proibidas, de sofrimento desnecessário gerando desde a incapacidade até a morte com o agravante de que a manipulação nanométrica pode controlar facilmente a disseminação dos agentes químicos e biológicos:

The ability of nanotechnology to design and manipulate molecules with specific properties could lead to bio/chemical agents capable of causing defined hostile results ranging from temporary incapacitation to death, or multilayered biochemical carriers that could easily control the spread of bio/chemical agents. (NASU, 2012, pp. 660)

Assim como na indústria tradicional a nanotenologia proporciona uma reviravolta na produção e desenvolvimento dos mais distintos produtos militares. Embora a possibilidade dos robôs em miniatura venha a se concretizar no futuro, a aplicação da nanotecnologia no ambiente militar também será enquanto insumo para a gama de produtos já desenvolvidos e que servem aos exércitos e grupos armados não Estatais. 
Quando se estudam as questões de regulamentação e regulação existe uma dicotomia a ser lembrada. Conforme exposto no capítulo inicial desta tese, existe uma diferença não somente conceitual, mas substantiva entre um modelo regulamentatório e outro regulatório. Enquanto o primeiro leva em consideração uma perspectiva unidirecional com fundamentos no monopólio do Estado, o segundo busca, a partir de uma compreensão sociológica, uma conjunção de elementos e instituições que busquem uma estabilidade harmônica de expectativas entre os envolvidos na sociedade. Essa discussão se mostra importante pois não se está simplesmente restringindo a nanotecnologia, seu uso militar, mas inclusive a perspectiva de regula(menta)r a inovação.

Os interesses na regulação podem ser os mais diversos já que este novo campo científico congrega interesses os mais diversos - lembrando que a atuação política é sempre baseada no binômio maioria/minoria quando da produção de decisões vinculantes à coletividade (Cf. CORSI, et all, 1996). Existem aqueles que buscam incentivo financeiro para o desenvolvimento das pesquisas, outros querem ter garantias para a produção e comercialização enquanto que outros querem delimitar as áreas e riscos até chegar aos que, a partir dos riscos que pode apresentar, a aplicação da precaução e a consequente cessação das atividades com nanotecnologias - somente para relacionar poucos exemplos.

Quanto aos usos militares, não existe hoje referência - ao menos no Brasil acerca de restrições expressas senão as previstas em tratados internacionais e as precauções habituais previstas na Constituição Federal. Embora as preocupações com a aplicação militar estejam em ritmo crescente como apontado anteriormente, desconhecese a prática industrial brasileira acerca dessa produção.

Associado a esta inércia da comunicação política, emerge a situação da regulação autônoma voluntária, global, adotando padrões limitando os avanços das pesquisas com nanotecnologias por diferentes critérios, que dentre eles inclui o risco futuro. Tal institucionalização, mesmo que muitas vezes privada, busca instrumentalizar o Direito à uma efetiva regulação para o qual normalmente se encontrava indiferente. (TEUBNER, 1989, p. 154)

Dessa forma pode-se avançar para a problematização da ideia da consequente fragilização da soberania em torno da regulação global em torno dos limites aos avanços 
tecnológicos oriundos das nanotecnologias e seus riscos. Como cada sistema, organização, compreende distintamente cada fenômeno, pauta-se como problemática da regulação jurídica é como se pode dar, de forma qualificada, um aprendizado mútuo entre sistemas quando da comunicação jurídica: “o problema de cada nova regulação jurídica é a questão aberta sobre o processo concreto de aprendizado com o qual a comunicação social adapta-se à comunicação jurídica e vice-versa" (TEUBNER, 2005, p. 49).

Neste aprendizado mútuo não se pode olvidar o papel das organizações, especialmente pela característica transnacional associada a elas, no gerenciamento dos riscos oriundos das nanotecnologias. Conforme mencionado anteriormente, o Direito enquanto sistema que opera de maneira autopoiética em uma sociedade complexa e contingente tem de estar atento a sua característica policontextural e dessa maneira induzir o cumprimento voluntário por parte das empresas daquilo que o mesmo considera legal: “[...] a produção sistêmica de riscos e sua evolução adequada na empresa faz com que seja necessário um gerenciamento de risco (risk management) empresarial a longo prazo através da precaução e da adaptação.” (DÍEZ, 2013, p. 16)

A ausência de regulação específica não pode ser percebida como ausência de resposta jurídica acerca da questão - como se percebe em certa medida quanto às nanotecnologias. Quanto aos usos militares está claro que as historicamente constituídas Convenções de Genebra se aplicam em qualquer conflito armado e consequentemente trazem restrições à guerra e aos meios que se utilizam em momentos de hostilidade. Compreensões jurídicas já existem e podem ser aplicadas, embora não exista um marco legal específico como já abordado.

Apostar na exclusividade do Estado para regular a sociedade já não encontra bases em uma sociedade e um Direito policontextural e, nesse sentido, é possível que as próprias organizações privadas implementem programas voluntários de cumprimento de normas que tenham sincronismo, e até mais robustez, com o que o Direito tem a dizer da matéria: dando uma efetiva gestão empresarial do risco mesmo quando aparentemente exista a ausência de decisões políticas vinculantes sobre a matéria. Conforme já expressado, a regulação ${ }^{4}$ das nanotecnologias - e seus usos militares - implica na

\footnotetext{
${ }^{4}$ Adota-se aqui a concepção de regulação, em detrimento da regulamentação, como tal abordada por Alain Supiot, de forma a controlar a entropia a partir da tríplice da informação, procedimento e negociação frutos da sociedade da comunicação. Tal distinção será abordada com a profundidade necessária no quarto capítulo. (Cf. SUPIOT, 2007, p. 155 e seguintes)
} 
realidade observar também a restrição à inovação. Isso se traduz também em regulação do conhecimento.

\section{DESAFIOS DA REGULA(MENTA)ÇÃO}

Este capítulo tende a não somente apresentar esta nova categoria de instrumento jurídico - os programas de integridade - mas, principalmente, refletir nele enquanto fonte de Direito para a regulação acerca dos usos militares das nanotecnologias em uma sociedade que se considera global. Conhecido por um arcabouço jurídico voluntário surgido no seio de corporações, hoje tais códigos de conformidade estão disseminados pelas mais distintas organizações, sejam públicas, privadas ou sem fins lucrativos.

Tendo sua origem relacionada a instrumentos anticorrupção, hoje ainda há uma grande ligação desses programas a tal contexto. Todavia hoje existe uma crescente compreensão de que o estabelecimento de programas de integridade pode vir a ter diferentes contornos e profundidades quando do fomento de prevenir e detectar condutas criminosas ou distantes da integridade desejada pela organização, bem como da promoção de uma cultura de cumprimento do contexto normativo e ético da empresa. (SERPA, 20016, p. 134)

Trata-se de instrumentos de buscam estabelecer acordos organizacionais, vinculando as decisões e condutas não exclusivamente internas daquela instituição, mas também e em muitas vezes por meio de um complexo arcabouço contratual envolvendo, outrossim, um emaranhado de organizações e processos. Ao passo que "[...] los acuerdos marcan, al mismo tiempo, límites de sistemas y subsistemas", eles "unen y separan de otros con los cuales los acuerdos son considerados inútiles o imposibles [...]”, estabelecendo e seguindo "[...] las líneas de diferenciación del sistema." (LUHMANN, 2010, p. 245)

A existência de tais instrumentos cada vez se demonstram mais apropriados, resguardadas as suas características, em uma sociedade fragmentada e global. Essa fragmentação proporciona, como consequência, diferentes subsistemas sociais autônomos e com eles novas barreiras entre os sistemas e o ser humano. Mas principalmente vai tratar de regular as tendências expansionistas dos subsistemas fomentando decisões que estejam em ressonância com os demais sistemas sociais: 
The fragmentation of world society into autonomous subsystems creates not only new boundaries outside society between subsystem and human being, but also new boundaries between the various subsystems inside society, on which the expansionist tendencies of the subsystems work in their specific ways. (TEUBNER, 2012, p. 145)

Os programas de integridade, a partir da sua existência e fomento, permitem uma análise qualificada entre a responsabilidade e responsabilização. Em certa medida já abordado no capítulo anterior, a responsabilidade possui uma relação muito estreita tanto com o aprendizado - neste caso organizacional - quanto com a relação de regulação. Por esse motivo o tema da formulação de regras internas, voluntárias e vinculantes, parece apropriado no cenário de uma sociedade global que já não se permite atuar somente a partir das fronteiras dos Estados nacionais.

O contexto global da sociedade contemporânea não expõe somente a ineficiência do tratamento de riscos globais pelos Estados e suas pretensas exclusividades, mas também indica a insuficiência de um modelo que foca na represália da sanção ao contrário de estimular aprendizagem recíproca entre os sistemas e organizações envolvidas. Por esse motivo que se tem abordado de forma recorrente a diferença entre regulação e regulamentação, bem como a relação entre responsabilidade e aprendizagem.

Estimular a responsabilidade e o aprendizado implica em reconhecer limites de auto-organização das organizações. Modelos de estímulo ao desenvolvimento e qualificação da autonomia com a apresentação de benefícios às organizações que operem com processos responsáveis de aprendizagem possuem relação próxima com a qualificação dos programas de integridade.

A fragmentação dos elementos de proteção está relacionada com a capacidade de os sistemas sociais sofrerem irritações fruto do acoplamento estrutural entre os sistemas sociais e as consciências. Neste ponto encontra-se a força da autoconstitucionalização: as irritações recíprocas entre sociedade e indivíduos, ou seja, entre comunicação e consciências. Essa forma propicia a emergência de novos potenciais comunicacionais, energia social fruto da conexão reflexiva entre consciências e a sociedade. A nova compreensão das organizações acerca de sua responsabilidade social é um dos exemplos de mudança do padrão da sociedade potencializando novas perspectivas da comunicação por parte dos mais diferentes sistemas sociais. A "social responsibility has been defined or conceptualized in a number of different ways, by 
writers of stature in business, and in its various definitions the term has encompassed a wide range of economic, legal, and voluntary activities." (CARROLL, 1979, p. 498)

Diferentes são as perspectivas relacionadas com a CSR. Dentre as expoentes podem ser citadas as seguintes perspectivas: a orientada por estratégia; a com foco em todos os interessados; a de cunho ético e, por fim, a orientada pela política nacional. A primeira entende que a responsabilidade social seria parte integral do processo de geração de riqueza, ou seja, compreendendo as novas medidas de cunho social a partir do critério custo-benefício. A segunda perspectiva busca o alinhamento da visão interna com os interesses de todas as partes envolvidas tais como acionistas, consumidores, empregados, fornecedores, comunidades, reguladores e outros grupos de interesse e toda a sociedade de forma a demonstrar o compromisso da organização e sua responsabilidade com relação a eles. Já a perspectiva de cunho ético identifica as empresas como seres humanos e nesse contexto possuiriam uma obrigação natural de atuar em benefício da sociedade como um todo ao mesmo tempo que não produziria dano aos outros. Por fim, a perspectiva política identifica a necessidade da imposição de padrões de CSR às empresas, especialmente para as multinacionais, por meio de normas jurídicas estatais - levando em conta a pressão de atores que possuem uma agenda contra às corporações. (Cf. TRICKER, 2015, p. 220 e seguintes).

Ultimamente tem ocorrido uma tendência de fragmentação daquilo que normalmente era centralizado, da família ao Estado. Se de um lado a modernidade primava pela unificação, hoje a crescente multiplicidade de diferenciações, tais como nacionais, locais, plurais, particulares, religiosas, sexuais, fomentam uma complexidade nos sistemas. Não seria diferente no sistema jurídico com a pluralidade de normas particulares e específicas em contraponto com as normas jurídicas gerais e abstratas historicamente reconhecidas como exclusividade dos Estados nacionais:

Las normas jurídicas generales y abstractas, corolario de exigencias éticas
universales, están siendo hoy cuestionadas en nombre de las preferencias
particularistas fragmentarias; la propia legitimación ética del Derecho y de la
Política, basada en principios consensuales universalizables, se considera un
ideal vacío y sospechoso de encubrir uniformismos totalitarios. A la unidad del
ethos moderno se opone la fragmentación y multiplicidad de ethos basados en
las diferencias « «nacionales», «locales», «plurales», «particulares»
(minorías étnicas, religiosas, lingüísticas, sexuales...). (grifo do autor) (LUNO,
1996, p. 13)

Em certa medida existem fundamentos desse processo na política internacional.

Se visualizado, existem três fenômenos exponenciais. De um lado os Estados nacionais 
estão transferindo funções governamentais para o nível transnacional e reconhecendo funções exercidas por atores não estatais. De outro é possível visualizar a criação de normas sem a legitimidade democrática em decorrência dos efeitos extraterritoriais das ações dos Estados nacionais. Por fim, inserido no contexto de desordem na sociedade global, não é possível visualizar um mandato democrático e, portanto, legítimo para a governança transnacional:

The weakness of international politics is said to be responsible for the disarray in global society. Three phenomena are prominent: (1) nation states are deconstitutionalized by the transfer of government functions to the transnational level and, at the same time, the partial assumption of these functions by nonstate actors; (2) the extra-territorial effects of nation-state actions create a law without democratic legitimation; (3) there is no democratic mandate for transnational governance. (TEUBNER, 2012, p. 5)

Essa regulação passa pela constitucionalização. Se de um lado a função central do Direito produzido pelo Estado nação é organizar, generalizar, as expectativas de comportamento, no Direito produzido transnacionalmente ocorre uma orientação destinada a estabelecer redes de transferência e co-adaptação (Cf. KJAER, 2013). Tanto sistemas como organizações são capazes de se constitucionalizar, ou seja, criar seu próprio código binário que submete suas comunicações ao que é constitucional/inconstitucional que, consequentemente, será seu código constitucional.

O constitucionalismo organizacional é, na realidade, a concretização do programa de decisão. Por tal motivo é importante identificar as características pelas quais essa programação se materializa. Como já abordado, a programação condicional é fundada no passado por remeter a decisão a uma prescrição previamente estabelecida. Normalmente ela está relacionada com uma conclusão lógica, senão até mesmo mecânica. Por outro lado, os programas com orientação finalística, que mesmo inevitavelmente orientados por certa programação inicial, as decisões são orientadas às consequências permitindo, associado a uma capacidade reflexiva profunda, a construção de horizontes comunicacionais distintos daquela programação inicial.

Têm-se constante reorganização não somente da sociedade, mas, principalmente dos sistemas sociais e organizações é devido à característica dinâmica da comunicação. Não poderia ser distinta a questão da regulação. Tem-se, por conseguinte, o desafio de que o sistema jurídico operacionalize a seus processos comunicacionais, e logicamente de tempo, de forma a buscar um maior sincronismo em face da sociedade contemporânea. 
Corporações multinacionais podem tirar vantagem das diferenças entre regimes regulatórios territoriais. O cenário de fragmentação de normas internacionais permite distintas regulamentações sobre vários aspectos realizada por conta dos distintos Estados. Dessa forma quando determinada entidade multinacional não possui apreço por determinado contexto legal, pode deixar de atuar em determinado Estado e privilegiar outro já que aqueles marcos nacionais, dentro de uma perspectiva conservadora, não atingem sua atividade em outros cenários.

Multinational corporations may take advantage of differences in territorial
regulation in deciding the nature and character of local investment, especially
in a legal context in which the free movement of capital is encouraged. Since
more than one state can regulate various aspects of the operations of a
multinational corporation, the latter might be able to evade regulation by a
strategic elaboration of its operations. When a multinational entity does not
like a particular regulatory scheme, it can leave and a regulating state cannot
reach the activities of entities subject to the substantive regulation of other
states. (BACKER, 2016, p. 6)

A emergência de normas globais, autoproduzidas por organizações privadas são um novo exemplo da contratualização do Direito a partir de centros e periferias. Historicamente as atividades de atores privados têm sido reguladas pelos contextos jurídicos de cada Estado, todavia, cada vez mais os entes públicos possuem dificuldade de dar efetividade a regulação quando se trata de atividades transnacionais de empresas que atuam globalmente.

A distinção entre regulamentar e regular leva a campos distintos de observação e de tratamento do assunto objetivado. Apoiando-se em Alain Supiot é que se defende que "regulamentar é ditar regras do exterior, ao passo que regular é fazer que se observem as regras necessárias ao funcionamento homeostático de uma organização" (SUPIOT, 2007, p. 159), ou seja, regulamentar trata de unilateralmente forçar aos demais a seguirem aquelas determinações. Porém, regular, mostra-se enquanto alternativa viável pela busca de cooperação e sinergia entre os interessados a partir de métodos e instrumentos de acomplamento estrutural que permitam processos sistêmicos de provocação, ou irritação - em termos sistêmicos, mútua trazendo a dinamicidade necessária para organização das expectativas sociais.

A problemática da regulação ora proposta visa identificar instrumentos que potencializem condições de acoplamento estrutural estável por meio de aprendizagens mútuas em um horizonte de condições frágeis dentro de uma multiplicidade de discursos. Mas vale lembrar que a regulação não pode ser algo visando somente preservar a 
atividade científica ou a atividade econômica. Em decorrência da sociedade global há um crescente número de processos comunicativos autônomos e muitas vezes anônimos, transnacionais, que ameaçam sobremaneira a sociedade.

Dessa maneira os direitos constitucionais podem ser compreendidos como um complemento histórico da diferenciação social. Ou seja, em decorrência da fragilidade imposta ao Estado moderno pela multiplicidade de discursos sociais autônomos é que a emergência de direitos constitucionais como instituições sociais previnem, embora nem sempre integralmente, a expansão total de determinados sistemas frente aos demais (TEUBNER, 2000, p. 413). Sendo o cenário transnacional ocupado de maneira expressiva por organizações, sejam internacionais, empresariais ou até mesmo sem fins lucrativos é que se propõe uma atenção especial para uma diferente observação dos critérios de culpabilidade, responsabilização e aprendizado a partir não exclusivamente das pessoas, mas também das organizações.

Com o Sistema do Direito compreendendo a si mesmo enquanto complexo, contingente e policontextural e inserido em uma sociedade global e de risco é que se apresentam os programas de integridade - ou programas de compliance do original do inglês - como alternativa para a regulação dos mais distintos temas. Tratam-se de um arcabouço normativo interno às organizações, sejam privadas por excelência ou sem fins lucrativos e internacionais, que surgem de forma espontânea, embora por vezes estimulada, visando não somente preservar a integridade organizacional, mas, promover uma cultura e complexidade interna e amadurecimento desta organização - sempre tentando integrar-se de maneira compatível com o preconizado pela comunicação jurídica policontexturalizada.

A importância de tais programas é justamente o regime transnacional e autônomo que eles alcançam. Embora particulares, autônomos e voluntários, eles alcançam as relações não somente internas, mas também eventualmente alcançam sua rede de relações que, por meio de contratos, permitem uma co-operação e aprendizagem mútua entre organizações e sistemas jurídicos autônomos. Alguns vão ter seu início na tentativa de coibir práticas ilicitas - como no caso dos programas anticorrupção amplamente utilizados, outros visando promoção de práticas trabalhistas mais adequadas e de satisfação, práticas ambientais sustentáveis que, nada impedem que possam vir a se tornar mais complexos. 


\section{CONCLUSÕES}

O quadro exposto de grande complexidade envolvendo o uso bélico de uma inovação tecnológica - no caso as nanotecnologias - em um cenário de incertezas internacionais - senão globais - qualifica a postura que o sistema jurídico deve desempenhar na contemporaneidade. As dificuldades do Estado nacional em lidar não servem de lápide mas, sim, de grande mote para o desenvolvimento e reconhecimento de novos instrumentos de regulação que, embora não desempenham o papel definitivo, podem trazer eficácia na institucionalização de garantias fundamentais na ordem global na qual os Estados nacionais não alcançam agir.

É neste cenário que perspectivas como a trazida pela regulação do Estado associada com mecanismos privados de coordenação de expectativas organizacionais podem trazer determinados benefícios, especialmente na gestão compartilhada de riscos oriundos da inovação tecnológica. Os programas de compliance se apresentam como um instrumento hoje global que, por meio da contratualização das relações, proporciona um aprendizado institucional com uma perspectiva de responsabilidade social de tal organização.

Obviamente que tais programas não são hoje a solução de todos os problemas relacionados a eficácia dos direitos fundamentais e os riscos à que a sociedade está submetida pelo uso militar das nanotecnologias. O que se buscou comprovar, por meio da solução da problemática é a possibilidade de endereçamento desta temática por outros meios que não somente a exclusividade da regulamentação pública estatal. 


\section{REFERÊNCIAS}

ALTMANN, Jürgen. Military nanotechnology: potential applications and preventive arms control. Londres/Nova Iorque: 2006.

BECK, Ulrich. A reinvenção da política: rumo a uma teoria da modernização reflexiva. In: __ Ulrich; GIDDENS, Anthony; LASH, Scott. Modernização reflexiva: política, tradição e estética na ordem social moderna. São Paulo: Editora da Universidade Estadual Paulista, 1997.

BORA, Alfons. Capacidade de lidar com o futuro e responsabilidade por inovações: para o trato social com a temporalidade complexa. IN: SCHWARTZ, Germano. Juridicização das esferas sociais e fragmentação do Direito na sociedade contemporânea. Porto Alegre: Livraria do Advogado, 2012, pp. 127 - 146.

BORGES, Isabel C. P.; GOMES, Taís F.; ENGELMANN, Wilson. Responsabilidade civil e nanotecnologias. São Paulo: Atlas, 2014.

CARROLL, Archie B. A Three-dimensional conceptual model of corporate performance. The academy of management review. n. 4 (4), p. 498. 1979. Disponível em: <http://www.jstor.org/stable/257850>. Acesso em: ago. 2016.

DÍEZ, Carlos Gómez-Jara. A responsabilidade penal da pessoa jurídica e o dano ambiental: a aplicação do modelo construtivista de autorresponsabilidade à Lei 9605/98. Porto Alegre: Livraria do Advogado Editora, 2013.

DREXLER, Eric. Engines of Creation: the coming era of nanotecnology. Nova Iorque: Anchor, 1986.

ENGELMANN, Wilson. A (re)leitura da teoria do fato jurídico à luz do 'diálogo entre as fontes do direito': abrindo espaços no direito privado constitucionalizado para o ingresso de novos direitos provenientes das nanotecnologias. In: CALLEGARI, A. L; STRECK, L. L; ROCHA, L. S (Org). Constituição, Sistemas Sociais e Hermenêutica. Porto Alegre: Livraria do Advogado, 2010, pp 289-308.

HENLEY, Lonnie D. The RMA after next. Parameters. Winter 1999/2000, pp. 46-57.

INTERNATIONAL COMMITTEE OF THE RED CROSS. International Humanitarian Law and the challenges of contemporary armed conflicts. Geneva: outubro, 2005, disponível em <http://www.inew.org/site/wpcontent/uploads/2015/11/32IC-Report-on-IHL-and-challenges-of-armed-conflicts.pdf >, Acesso em: ago. 2016.

JOY, Bill. Why the future doesn't need us. Disponível em <http://archive.wired.com/wired/archive/8.04/joy_pr.html>, Acesso em: fev. 2016. 
KJAER, Poul F. Trasnational normative orders: the constitutionalism of intra- and transnormative law. Indiana Journal of Global Legal Studies, Indiana, v. 20, n. 2, p. 778, p. 777-803, 2013.

LEITE, José Rubens Morato; AYALA, Patryck de Araújo. Direito ambiental na sociedade de risco. Rio de Janeiro: Forense Universitária, 2004.

LUHMANN, Niklas. La sociedad de la sociedad. México: Herder, 2007.

LUHMANN, Niklas. Organización y Decisión. Cidade do México: Herder, 2010.

LUÑO, Antonio-Enrique Pérez. Derechos Humanos y Constitucionalismo en la actualidad. In: LUÑO, Antonio-Enrique Pérez. Derechos Humanos y Constitucionalismo ante el tercer milenio. Madrid: 1996.

NASU, Hitoshi. Nanotechnology and challenges to international humanitarian law: a preliminary legal assessment. International Review of the Red Cross. Genebra, volume 94, n. 866, pp. 657-658, summer 2012, 2012. Disponível em: < https://www.icrc.org/eng/assets/files/review/2012/irrc-886-nasu.pdf>. Acesso em: ago. 2016.

PEIXOTO, Flávio José Marques. Nanotecnologia e sistemas de inovação: implicações para a política da inovação no Brasil. 2013. 398 f. Tese (Doutorado em Economia) Programa de Pós-Graduação em Ciências da Comunicação, Universidade Federal do Rio de Janeiro - UFRJ, Rio de Janeiro, RJ, 2013.

PHOENIX, Chris; TREDER, Mike. Nanotechnology as global catastrophic risk. IN: BOSTROM, Nick; CIRKOVIC, Milan M. Global Catastrophic Risks. Oxford: Oxford University Press, 2008, pp. 481-503.

POLÍTICA. In: CORSI, Giancarlo; ESPOSITO, Elena; BARALDI, Claudio. Glosário sobre la teoría Social de Niklas Luhmann. México: ITESO/Editorial Anthropos, 1996.

ROCHA, Leonel Severo; SCHWARTZ, Germano; CLAM, Jean. Introdução à Teoria do Sistema Autopoiético do Direito. Porto Alegre: Livraria do Advogado, 2005.

ROCHA, Leonel Severo. Epistemologia jurídica e democracia. 2 ed. São Leopoldo: Editora Uinisinos, 2003.

SERPA, Alexandre de Cunha. Compliance Descomplicado: um guia simples e direto sobre programas de compliance. Editora Createspace Independent Publishing Platform: 2016.

SUPIOT, Alain. Homo juridicus: ensaio sobre a função antropológica do Direito. São Paulo: Martins Fontes, 2007.

TEUBNER, Gunther. Constitutional Fragments: societal constitutionalism and globalization. Translated by Garteh Norbury. Oxford: Oxford University Press, 2012.

Rev. de Direito, Inovação, Propriedade Intelectual e Concorrência| e-ISSN: 2526-0014| Maranhão | v. 3 | n. 2 | p. 1 - 21 | Jul/Dez. 2017. 
TEUBNER, Gunther. Direito, sistema e policontexturalidade. Piracicaba: Editora Unimep, 2005.

TEUBNER, Gunther. O Direito como sistema autopoiético. Tradução de José Engracia Antunes. Lisboa: Fundação Calouste Gulbenkian, 1989.

TRICKER, Bob. Corporate Governance: principles, policies, and practices. Oxford: Oxford University Press: 2015.

BACKER, larry Catá. Multinational corporations as objects and sources of transnational regulations. ILSA Journal of International \& Comparative Law. Vol. 14. n. 2, p. 6, 2008. Disponível em: <http://ssrn.com/abstract=1092167>. Acesso em: ago. 2016. 